\title{
La cuestión del archivo desde una perspectiva warburguiana: huellas, pathos, dinamogramas
}

\section{(4) Daniela Losiggio}

Consejo Nacional de Investigaciones Científicas y Técnicas - Universidad de Buenos Aires - Universidad Nacional Arturo Jauretche, Argentina.

\begin{abstract}
Natalia Taccetta
Consejo Nacional de Investigaciones Científicas y Técnicas - Universidad de Buenos Aires - Universidad Nacional de las Artes - Universidad Nacional de Tres de Febrero, Argentina.
\end{abstract}

\section{Introducción}

En la actualidad, la noción de "archivo" remite incansablemente a la arqueología de Michel Foucault de fines de los años 1960 (especialmente a Arqueología del saber de 1969), así como a las reflexiones de Jacques Derrida (en torno a su obra Mal de archivo de 1995). ${ }^{1}$ Sin perjuicio de esas elaboraciones, que no resultan incompatibles con lo que aquí nos ocupa, reconducimos la preocupación por el archivo hacia la apuesta de Aby Warburg en la década del veinte del pasado siglo como un desafío a las teleologías en la Historia del Arte y una problematización de la idea misma de canon.

Siguiendo esas líneas maestras, autores como Hal Foster (2004) o Anna Maria Guasch (2011) proponen hoy que la cuestión del archivo reconfigura los modos de la representación histórica y artística al tiempo que impone un modelo de artista que hace del archivo su marca generativa de modo casi sistemático. Pensado en este marco, se trata asimismo de un dispositivo que desafía la idea modernista de totalización y aspira a algún tipo de contacto entre experiencia histórica y realidad artística. En este mismo sentido, el historiador Benjamin Buchloh viene echando mano de la noción de archivo para poner en jaque la preferencia historiográfica por el almacenamiento o la colección de documentos, pues archivar entraña el establecer relaciones inmanentes y complejas entre pasado y presente.

Buchloh describe el paradigma del archivo como aquel que implica una creación basada en una "secuencia mecánica" (Guasch, 2011: 9), una serie repetitiva que se organiza sobre lo que denomina "estética de organización legal-administrativa" (Buchloh, 1999: 32). No se trata de almacenar o coleccionar, pues archivar no es asignar un lugar a una imagen, objeto o acontecimiento en una narrativa, sino que se vincula con el 
2. Se trata de una colección de fotografías, retratos familiares, recortes de diarios y dibujos que el artista juntó desde la década de 1960 y que hacia 1970 comenzó a reunir en hojas sueltas. Actualmente tiene más de 800 páginas que reflejan diferentes fases en la vida y el trabajo de Richter. "consignar", esto es, identificar, clasificar y localizar para coordinar un corpus en un sistema determinado que apunta a establecer relaciones entre sus componentes e indaga sobre los significados que pueden establecerse a partir de ellos.

En la búsqueda de nuevos modos de abordar el archivo repensando la relación entre presente y pasado, se vuelve fundamental recoger algunas ideas del famoso texto que Buchloh dedica al Atlas de Gerhard Richter, ${ }^{2}$ dispositivo heredero del célebre Atlas Mnemosyne de Warburg, al que nos referiremos particularmente. Habida cuenta de que los términos collage o fotomontaje no describen adecuadamente las operaciones allí realizadas, Buchloh advierte que no hay en la historia del arte términos o géneros definidos que puedan ajustarse a estas propuestas. En efecto, está seguro de que la idea misma de "atlas" resulta familiar al habla alemana -pues existen libros que se ajustan a esa definición desde fines del siglo XVI-, pero que en inglés hay que esperar hasta el siglo XIX para encontrar cada vez más frecuentemente "cualquier muestra tabular de conocimiento sistematizado" como los preferidos del positivismo. Para Buchloh, finalmente, el siglo XX hizo caer el término "archivo" en el terreno de la metáfora, con lo que declinaron definitivamente "la confianza en el empirismo y la aspiración hacia la completitud comprensiva de los sistemas positivistas de conocimiento" (Richter, 2006: 86-87).

Es en las primeras décadas del siglo XX cuando aparecen lo que Guasch llama "las dos máquinas de archivo" en el campo de las ciencias humanas: la que pone énfasis en el principio regulador de la ley y el orden topográfico y la que acentúa los procesos derivados de las acciones de almacenar y olvidar, de guardar y destruir, atendiendo a la pulsión de destrucción que Derrida describe en su ensayo sobre el mal de archivo. Diversas propuestas de esa época se explican por alguno de esos principios. El montaje literario de Walter Benjamin en el Libro de los pasajes - proyecto filosófico iniciado hacia 1927 e inconcluso debido a la muerte de su autor-y el archivo fotográfico de August Sander se identifican con los principios de procedencia, homogeneidad y continuidad. Sin embargo, el montaje visual de Warburg se identifica de modo más evidente con la pulsión de heterogeneidad y discontinuidad, esto es, con lo que Buchloh llamaría "archivo anómico".

A los efectos que estos autores se proponen, el Atlas Mnemosyne constituye un antecedente ineludible en el intento de dar cuenta de un pasado que ni es lineal ni se ajusta a parámetros a priori, sino que tiene su propia existencia. Warburg confió plenamente en las afinidades afectivas entre el complejo de la experiencia presente y las pasadas; del mismo modo, creyó que esto podía expresarse de modo eminente a partir de un archivo de imágenes.

Nos abocaremos ahora a la revisión de la influencia del biólogo Richard Semon en el pensamiento de Aby Warburg, especialmente en la creación de la noción de "dinamograma". Esta permitirá echar luz sobre el proyecto archivístico del Atlas Mnemosyne así como, en un segundo momento, analizar el legado warburguiano: tanto un modo alternativo de pensar la historia en términos disciplinares como una crítica implícita al vínculo con las relaciones de poder que las tecnologías del registro y la clasificación parecen poner en funcionamiento.

\section{Memoria y dinamogramas: el retorno del pathos}

Proponemos como punto de partida una definición de archivo articulada a partir de la obra warburguiana: montaje no-narrativo que construye un vínculo con el pasado por medio de una raíz común, la similitud del afecto presente con el complejo 
afectivo pasado. Para explicar esta definición, es necesario, por un lado, referirnos a la teoría de Richard Semon y, por el otro, a los modos en que esta teoría impactó en el proyecto del Atlas Mnemosyne.

En efecto, Semon, seguidor del gran psicólogo del siglo XIX Edward Hering, fue el autor que inspiró el concepto warburguiano detrás de Mnemosyne. El libro de Semon Die Mneme als erhaltendes Prinzip im Wechsel des organischen Geschehens [La Mneme como principio conservado en la modificación del suceso orgánico, 1904] propone la tesis general de que la memoria no es una propiedad de la consciencia, sino el elemento definitorio de la materia viva (Gombrich, 1992: 228).

Todo lo que afecta a la materia, todo input o complejo de estímulos, deja una huella a la que Semon llama "engrama". El engrama o huella mnemónica es también un complejo energético, un conjunto simultáneo de energías (excitaciones) que se almacenan en la materia. El engrama reaparece cuando es convocado por un elemento similar a algún componente del complejo original de estímulos. Así es que, para esta teoría, existe una diferencia entre el input y el output, entre la conservación y la transmisión. La memoria se conserva como huella, como complejo energético; y se transmite, fragmentariamente, reconfigurándose, cuando es convocada por el presente (Schacter et. al., 1978). Dicho de otra manera: la materia semoniana está "viva" en tanto constituye un reservorio fragmentario y complejo de energías-afectos que puede seguir siendo convocado por un elemento energético en el presente y, al ser convocado, regresa en su fragmentariedad, no idéntico a sí mismo, sino como una novedad. La convocación o llamado energéticoafectivo del presente da, así, al complejo energético-afectivo o engrama un nuevo sentido.

La teoría warburguiana de la memoria se ve impregnada por dos aspectos de la doctrina de Semon: a) la memoria es tal en tanto materia viva, aquello que sobre-vive (nachlebt), simbólica y socialmente; b) la memoria se materializa cuando un dinamograma o huella energético-afectiva se combina con (es llamada por) un elemento energético-afectivo similar en tiempo presente, configurando una imagen o símbolo con nuevo sentido. En palabras de Giorgio Agamben:

El símbolo y la imagen realizan para Warburg la misma función que, según Semon, realiza el engrama [...]: en ellos se cristalizan una carga energética y una experiencia emotiva que sobreviven como una herencia transmitida por la memoria social y que [...] se vuelven efectivas a través del contacto con la voluntad selectiva de una época determinada (Agamben, 2007: 198).

Las supervivencias son materiales y tienen actualidad, sus efectos dependen del modo en que viven, actúan y afectan en el presente. El neologismo warburguiano "dinamograma" [Dynamogramm] cita la noción de engrama semoniano: constituye una huella afectiva del pasado que entra en diálogo, polariza o tensiona con un elemento del presente. ¿Cómo se comportan estos dinamogramas al interior de la memoria social?

Los dinamogramas del arte antiguo se transmiten en un estado de máxima tensión, pero sin polarizar con respecto a la carga energética [...] Solo el contacto con la nueva era da como resultado la polarización. Dicha polarización puede conducir a una alteración (inversión) radical (Warburg cit. en Gombrich, 1992: 223).

No podemos saber cómo polarizará un dinamograma porque no tenemos noticias de él más que en su materialidad actual (superviviente), es decir, en su encuentro con un presente que lo convoca.

Cabe aquí advertir sobre la relevancia de la imagen-afectiva como clave de inteligibilidad del pasado en toda la obra de Warburg. En pocas ocasiones, en su obra 
escrita, Warburg utiliza la noción de Pathosformel. La primera aparición tiene lugar en "Durero y la antigüedad italiana" (1905). Se dice allí que el motivo de Orfeo se había convertido, para el círculo de Mantegna, en una fórmula del pathos (2005: 404). Más tarde, en "Arte italiano y astrología internacional en el Palazzo Schifanoia de Ferrara" (1912), Warburg hace alusión a las "supervivientes [nachlebende] fórmulas del pathos [Pathosformeln] de procedencia griega" en el Renacimiento (2005: 415). La noción refiere así a un motivo antiguo que se reedita bajo la experiencia afectiva actual y esta idea es central en la obra de Warburg. En el descubrimiento de anacronismos, se ilumina una búsqueda que pretende demostrar que los esquemas de origen-esplendor-muerte de los estilos tienen tan poco asidero como una concepción cerrada de la historia. Así es como, por caso, Warburg puede ver en Botticelli un "estilo ideal, más elevado y a la antigua" que se independiza de las constricciones del realismo medieval para liberar la potencia de una belleza vinculada a figuras femeninas danzantes que despliegan una sensualidad inaudita en el ámbito sacro. Warburg encuentra allí a la ninfa "de cabellera alada y vestidos al viento, propios de la ménade griega o la Victoria romana" (Warburg, 1992: 77). Las diosas griegas que en pleno Renacimiento reconquistan la naturaleza despliegan una potencia extática impensable para un historiador convencional.

El gran proyecto de un atlas visual buscaba que las propias imágenes, reunidas mediante un pathos común (y no vía un prejuicio teórico o una linealidad a priori), produjesen el conocimiento histórico. Así, mediante su propia capacidad evocadora, los dinamogramas lograrían "definir, como ocurrió en la época del Renacimiento, el arte y la literatura del presente" (Rampley, 2000: 88).

Warburg anunció el plan del Atlas Mnemosyne en diciembre de 1927 (Gombrich, 1992: 252). El propósito original -interrumpido por la muerte de su impulsor, en 1929-era el de la publicación de tres volúmenes, uno de imágenes y dos de textos. El volumen de imágenes quedó conformado como un conjunto de fotografías de paneles que exponían diferentes reproducciones de imágenes agrupadas por un común Leitmotiv, como aquellos de "descenso", "rapto", "ascenso" o "superlativo del lenguaje", entre otros. Puede reconocerse en ellos el capítulo pictórico de los escritos warburguianos previos (Saxl, 2010).

De modo que este atlas no consiste en un ángulo picado o una mirada de pájaro que proyecta un conocimiento geográfico de dos dimensiones, como lo hacen las topografías convencionales (Weigel, 2013). Por el contrario, el Atlas Mnemosyne incluye la dimensión temporal que hace coincidir un conjunto de fórmulas del pathos de la cultura occidental, pertenecientes a distintas épocas, estilos y geografías. A un mismo tiempo, el Atlas es el proyecto de hacer de la memoria un espacio material, físico (un Denkraum); esto es, creando una suerte de "sensación del pasado" (Depetris Chauvin, 2015: 126). Mediante esta sensación, el pasado se vuelve material, física y espacialmente contemporáneo (Checa, 2010). Mnemosyne constituye, entonces, un terreno de experimentación visual, un atlas de signaturas históricas, cuya capacidad imaginativa conlleva una potencia epistemológica fundamental.

\section{Actualidad del archivo warburguiano}

En términos generales, podría señalarse que el archivo es "un depósito de escritos, un conjunto de testimonios, un registro de huellas, imágenes o sonidos" (De Mussy y Valderrama, 2010: 47). Implica almacenamiento y desciframiento, un esfuerzo de intelección y el establecimiento de alguna verdad inmanente. Conlleva una práctica de comprensión y un esfuerzo de legibilidad sobre un pasado, entendido como un pasado activo, con capacidad de actuar y afectar, por eso la reescritura está cargada de un impulso de justicia. 
Sin dejar de tener en cuenta que la noción de "archivo" involucra en el pensamiento actual una tradición que abreva en la filosofía de Foucault y en una tradición que se reinaugura en los años noventa con las reflexiones de Derrida en torno a lo que denomina "mal de archivo", reelaboraciones recientes de la noción recuperan el pensamiento warburgiano como una matriz crítica a la representación histórica convencional, como una perspectiva que asume la obra como un campo de batalla que interroga el tiempo y que apoya la deconstrucción de la tríada obra, período, autor como una necesidad radical para configurar una arqueología inédita del documento, cuestionando la idea de continuidad, propia de los historicismos heredados por el siglo XX.

En La arqueología del saber, publicado originalmente en 1969, Michel Foucault sostiene que la arqueología describe los discursos como prácticas específicas en el archivo. En este sentido, "archivo" resulta una noción que no refiere a la totalidad de los textos que una civilización conserva y tampoco implica la totalidad de las huellas que quedan, sino justamente el juego de las reglas que la cultura establece para determinar la aparición y la desaparición de los enunciados, el modo en que configura tejidos que sostienen su permanencia y su borradura, su existencia como acontecimientos y cosas. Dicho de otro modo, el archivo es el sistema de las condiciones históricas de posibilidad de los enunciados en tanto prácticas singulares y acontecimientos discursivos; es "la ley de lo que puede ser dicho, el sistema que rige la aparición de los enunciados como acontecimientos singulares" (Foucault, 2005: 219).

Siguiendo estas ideas, analizar los hechos discursivos -enunciados, objetos o prácticas culturales- en el ámbito del archivo implica asumir su carácter no de documentos (en tanto remiten a la significación que exige una tarea de desciframiento), sino de monumentos, es decir, "sin asignación de origen, sin el menor gesto hacia el comienzo de una arché" (Revel, 2008: 16). El arqueólogo foucaultiano no busca en los documentos huellas que quedaron de las prácticas, sino que los aborda como instrumentos que establecen relaciones clasificables y complejas con el presente. No trata a los documentos como signos de algo más - a descubrir-, sino que los describe como prácticas concretas -como la de construir relatos. En términos de Foucault, esto implica hacer arqueología. Hacer archivo conlleva aceptar, como parte del conjunto, los discursos efectivamente pronunciados en una época y que siguen existiendo a través de la historia -movimiento que Foucault realiza en su obra desde Historia de la locura en la época clásica en 1961 hasta La arqueología del saber-, ${ }^{3}$ pero también involucra comprender las reglas y condiciones de su funcionamiento tanto como las prácticas que los activan.

Como se ha mencionado, Foster o Guasch proponen que el giro al archivo como mecánica obliga a redefinir el concepto mismo de representación histórica y artística incorporando esta dimensión como cuestionamiento a las historiografías y cronologías hegemónicas. Esta perspectiva complejiza las aproximaciones usuales al archivo dado que intenta pensarlo como un dispositivo capaz de desocultar las estructuras discursivas y de poder que lo constituyen y, en cierto sentido, afirmar la necesidad de configurar archivos alternativos a las "grandes verdades" establecidas por los discursos de la historia y la memoria.

Si Foucault y Derrida establecieron los cimientos de una perspectiva que intentó cuestionar los modos de representar la historia y vincularse con ella, los debates inaugurados por pensadores de distintas disciplinas como Andrea Giunta, Cristián Gómez-Moya, Miguel Valderrama, Antoinette Burton, Hal Foster, Okwui Enwezor, Anna Maria Guasch, Ann Cvetkovich, entre otros, intentan trascender aquella primera aproximación y desplegar un enfoque que reivindique el archivo incluso como contrapráctica discursiva en la historia y el arte.
3. En Historia de la locura en la época clásica, Foucault concibe su práctica como una arqueología del saber, es decir, una disciplina que se ocupa del conocimiento en tanto episteme, es decir, un ámbito en el cual los conocimientos son abordados sin referencia a un valor racional u objetivo, sino una consideración del saber histórico como la pregunta por las condiciones históricas de posibilidad del saber. 
4. Su importancia no se agota allí, pues también alude a la capacidad de dar efecto, fuerza, valor o autenticidad a aquello que signan. El desarrollo crucial sobre la signatura debe partir del paradigma de signaturas por excelencia que es la lengua. Agamben sostiene que hay que entender la relación de semejanza en la forma de un modelo analógico e inmaterial y comprender la lengua como "el cofre de la signaturas". Para realizar este análisis, recurre como en otros tramos de su obra a Émile Benveniste y de aquí a Jakob Böhme, la tradición hermenéutica medieval, la teoría de los sacramentos, Marsilio Ficino, la magia, la influencia de la astrología en Aby Warburg y su teoría de los Pathosformeln (fórmulas del pathos). Mención aparte merece Las palabras y las cosas de Michel Foucault -referencia insoslayable para abordar la teoría de las signaturas en la episteme renacentista-y la remisión a La arqueología del saber para abordar la relación entre signatura y enunciado -"el enunciado es la signatura que marca el lenguaje por el puro hecho de su darse", sostiene Agamben (2009: 90). Hay en Foucault una exigencia de revisar metodológica -y ontológicamente- las estructuras del conocimiento respecto de la relación que se establece entre el saber de una época y lo que es pasible de ser dicho o incluso pensado en ella. Foucault se centra en "masas discursivas" que trazan el recorrido de las verdades posibles que pueblan los imaginarios. Cada época se define por las capas que entraman el esquema general del conocimiento.
En este marco es que proponemos un retorno a la propuesta warburguiana, en la medida en que retomar la importancia del pathos implica una nueva forma de pensar los modos de consignación, clasificación y representación de la temporalidad. Para Warburg, la memoria social colectiva podía ser rastreada a través de múltiples estratos de transmisión cultural. En efecto, a partir de su pensamiento se puede sostener que su intento se focaliza en el "nexo inextricable entre lo mnemónico y lo traumático" (Buchloh, 2006: 87). Por ello, Warburg quiso construir un modelo de memoria histórica y continuidad de la experiencia, un atlas que pudiera ser también un proyecto materialista de memoria social.

En Signatura rerum (2009), Giorgio Agamben produce una declaración metodológica sobre su propio proyecto filosófico, donde aborda el concepto de "signatura" que, de una manera escorzada pero fundamental, se puede desplazar para pensar la relación entre signatura e historia tanto como la influencia de Warburg en el trabajo agambeniano. Agamben se refiere a los índices, las marcas, los indicios que permiten advertir similitudes y configurar relaciones de semejanza entre las cosas. ${ }^{4}$ Es evidente también la presencia de estas ideas en la propuesta de otro especialista en Warburg como Georges Didi-Huberman cuando habla de una "arqueología del saber visual" para referir a las operaciones del Atlas Mnemosyne en tanto superposiciones de herencias entrelazadas -de modo consciente o no- en constante cambio y desplazamiento. Precisamente, asumiendo que el montaje es la operación principal en cualquier ejercicio historiográfico, Didi-Huberman examina la potencia política de las "concordancias imposibles" que llenan de nuevo significado las imágenes. El conflicto dialéctico entre imágenes encuentra su perfil en la colisión, en la explosión donde cada una de las trazas inaugura un curso posible. Aplicando un modelo freudiano, se dirá que lee las imágenes en la materialidad y el desplazamiento. Es así que produce una estética del síntoma tal como señala Maud Hagelstein:

[E]s decir, una estética que tiene en cuenta la sobredeterminación de la imagen. Una imagen sobredeterminada es una imagen cuyo sentido no es cerrado y unívoco, sino sin clausuras. La imagen posee una multiplicidad de sentidos; como una red, multiplica las posibilidades de sus recorridos de lectura (Hagelstein, 2005: 86).

En la lógica warburguiana, cada imagen se convierte en algo que constituye un fotograma en un gigantesco tramo de material fílmico. Es la imagen la que puede dislocar el todo e interrumpir y, con esta disrupción, modificar, revelar y solicitar las narrativas predecibles de la historia del arte. Esta se consideraba atada a líneas de organización reductivas que obligaban a pensar que había una narrativa que delineaba el modo en que el arte cambiaba y se desarrollaba a lo largo de los diferentes períodos.

El atlas no se limita a describir las migraciones de las imágenes a través de la historia de las representaciones, sino que las reproduce introduciendo en la historia del arte una forma de pensamiento "archivista", que busca efectos más que significados. La comparación frecuente con el medio cinematográfico (Michaud, 2004; Kluge, 2010: 299) radica en que la esencia del cine no reside solamente en el contenido de las imágenes, sino en la relación entre las imágenes. Principio cinematográfico fundamental, el montaje es una de las claves del archivo que produce lenguaje como sintaxis visual edificada sobre intervalos. En el atlas warburguiano, la dimensión subjetiva está desplazada al "entre" las imágenes; en el cine, ocurre algo similar en tanto el montaje se comporta como una operación material de sutura. El archivo-montaje es la ley que une los restos.

Explorar la perspectiva de Warburg implica, entonces, pensar la imagen como "instancia de intervención" y "campo de fuerzas" (Sierek, 2009: 15). Esto supone 
analizarla como la sustancia misma de la historia, el espacio de comprensión del presente y la articulación entre técnica, cultura y archivación. El objetivo de Warburg en Mnemosyne no radica únicamente en la reescritura de la historia alejada de la linealidad y los criterios disciplinares más tradicionales, sino que una de sus preocupaciones fundamentales se vincula con la puesta en evidencia del excedente afectivo que produce la inmaterialidad de las relaciones mentales que emergen de y entre las imágenes. En este sentido, Warburg se explaya sobre la imagen como espacio para el pensamiento. Parece tener un obvio heredero en las técnicas artísticas de construcción espaciotemporal de su época-como en las propuestas vanguardistas-y, especialmente, en la experimentación con el montaje cinematográfico que les es contemporánea. ${ }^{5}$

\section{Palabras finales}

A la luz de estas consideraciones es posible acordar que Mnemosyne pone en forma un problema epistemológico clave de la disciplina histórica como el de la representación desde la pura visualidad del archivo, esto es, sin la ayuda de las explicaciones teóricas que sobredeterminen significados. Intenta restituir para los documentos un lugar en el proceso histórico que no se desprende de la cronología, ni de teleologías definidas y definitivas, sino de lo que considera que es lo que con Warburg podría llamarse la "vida de las imágenes".

El archivo no es panegírico, pero tampoco desinteresado. Su principal objetivo es hacer lugar a las voces silenciadas de los tiempos. El giro contemporáneo puede ser leído en complementariedad con un giro materialista o afectivo que nos permite preguntarnos por la capacidad de actuar y afectar en las cosas sin incurrir en un irracionalismo. La huella orientadora de la investigaciones warburguianas legan una mensaje de enorme actualidad: las voces del pasado, decía en un famoso ensayo de 1904, quieren expresarse. Efectivamente estos restos tienen una enorme capacidad de conmover nuestros esquemas más rígidos de comprensión del mundo, que muchas veces encorsetan la acción y la vida en común.
5. Esto se constata de modo explícito en cineastas soviéticos como Sergei Eisenstein o Dziga Vertov que absorbieron la lógica conflictiva del constructivismo y la factografía -la confianza en la fotografía documental como herramienta política de la clase obrera- $y$, de modo menos ostensible, en la utilización emocional de los efectos de continuidad en perspectivas más hegemónicas. 


\section{Bibliografía}

"Agamben, G (2007). Aby Warburg y la ciencia sin nombre. En La potencia del pensamiento. Ensayos y conferencias (pp. 157-187). Buenos Aires: Adriana Hidalgo.

» Agamben, G. (2009). ¿Qué es un paradigma. En Signatura rerum. Sobre el método. Buenos Aires: Adriana Hidalgo Editora.

»Checa, F. (2010). La idea de imagen artística en Aby Warburg. El Atlas Mnemosyne (trad. Chamorro Mielke, J.). En Warburg, A., Atlas Mnemosyne. Madrid: Akal.

"De Mussy, L. y Valderrama, M. (2010). Historiografía postmoderna. Conceptos, figuras, manifiestos. Santiago de Chile: Ediciones Universidad Finis Terrae.

»Depetris Chauvin, I. (2015). Texturas del pasado, performances del presente. En Macón, C. y Solana, M. (Eds.), Pretérito indefinido. Afectos y emociones en las aproximaciones al pasado (pp. 113-133). Buenos Aires: Blatt \& Ríos.

"Foster, H. (2004). An Archival Impulse. October 110, pp. 3-22.

"Gombrich, E (1992). Aby Warburg. Una biografía intelectual. Madrid: Alianza.

"Guasch, A. (2011). Arte y archivo 1920-201. Genealogías, tipologías y discontinuidades. Madrid: Akal.

» Hagelstein, M. (2005). Georges Didi-Huberman: une esthétique du symptôme. $\Delta a i^{\prime} \mu \omega v$. Revista de Filosofía 34, 81-96.

»Kluge, A. (2010). La historia del cine viene con nosotros desde el futuro. En 120 Historias del cine (pp. 299-300). Buenos Aires: Caja Negra.

» Michaud, P. (2004). Aby Warburg and the Image in Motion (trad. Hawkes, S.). Nueva York: Zone Books.

» Rampley, M. (2000). The remembrance of things past. On Aby Warburg and Walter Benjamin. Göttingen: Harrossowitz-Wiesbaden.

"Saxl, F. (2010). Carta a la editorial B. G. Teubner (ca. 1930) (trad. Chamorro Mielke, J.). En Warburg, A., Atlas Mnemosyne. Madrid: Akal.

» Schacter, D.; Erich, J. y Tulving, E. (1978). Richard Semon's theory of memory. Journal of verbal learning and verbal behavior, 17, 721-743.

"Warburg, A. (1992). Arte italiana y astrología internacional en el Palacio Schifanoia de Ferrara. EN AA.VV. Historia de las imágenes e historia de las ideas. La escuela de Aby Warburg. Buenos Aires: Centro Editor de América Latina.

"Warburg, A (2005). El Renacimiento del paganismo. Aportaciones a la historia cultural del Renacimiento europeo (trad. Sánchez, E. y Pereda, F.). Madrid, Alianza.

»Warburg, A. (2010). Atlas Mnemosyne (trad. Chamorro Mielke, J.). Madrid: Akal.

"Warburg, A. (2010b). Werke. Berlin: Suhrkamp.

»Weigel, S. (2013). Epistemology of Wandering, Tree and Taxonomy. The System figuré in Warburg's Mnemosyne Project within the History of Cartographic and Encyclopaedic knowledge. Images re-vue, 4. Recuperado de: http://imagesrevues. revues.org/2934. 